\title{
Egg-larval opiine parasitoids (Hym., Braconidae) of tephritid fruit fly pests do not attack the flowerhead-feeder Trupanea dubautiae (Dipt., Tephritidae)
}

\author{
X. G. Wang ${ }^{1}$, A. H. Bokonon-Ganta ${ }^{1}$, M. M. Ramadan ${ }^{2}$ and R. H. Messing ${ }^{1}$ \\ ${ }^{1}$ Department of Plant and Environmental Protection Sciences, University of Hawaii, Kapaa, HI, USA; \\ ${ }^{2}$ Plant Pest Control Branch, Hawaii Department of Agriculture, Honolulu, HI, USA
}

Ms. received: May 4, 2004; accepted: October 12, 2004

\begin{abstract}
We investigated the potential impact of three opiine tephritid fruit fly parasitoids: Fopius arisanus (Sonan), Fopius caudatus (Szépligeti) and Fopius ceratitivorus Wharton, on the non-target native Hawaiian tephritid, Trupanea dubautiae (Bryan), infesting flowerheads of the endemic Asteraceae shrub Dubautia raillardioides Hillebrand. The three species are the only known opiine fruit fly parasitoids that attack host eggs (but occasionally attack first instars). F. arisanus, which originated in southeast Asia, is now widely established in Hawaii and elsewhere in the world, while the other two are African species currently in quarantine in Hawaii. In the laboratory, field-collected flowerheads of $D$. raillardioides containing $T$. dubautiae eggs and first instar larvae were exposed to naïve female wasps of each of the three Fopius species in the absence (no-choice test) or presence (choice test) of papaya fruit infested with eggs of the Mediterranean fruit fly Ceratitis capitata (Wiedemann), the parasitoids' normal host. All three Fopius species visited the papaya fruit much more often than the flowerheads, and displayed normal ovipositional responses (probing and stinging) on the fruit in the choice test. None of the three parasitoid species showed ovipositional responses to flowerheads in either choice or no-choice tests. As a result, not a single T. dubautiae egg or larva was attacked by any of the three parasitoids, indicating that these parasitoids of pest tephritids are unable to recognize the microhabitats of flowerhead-feeding tephritids. The results suggest minimal risk of non-target impact in these biological control agents.
\end{abstract}

Key words: Fopius arisanus, Fopius caudatus, Fopius ceratitivorus, Trupanea dubautiae, biological control, non-target test, parasitoids, tephritids

\section{Introduction}

Concerns regarding non-target impacts of introduced natural enemies have resulted in a tightening of regulations against classical biological control (Messing, 1999). In particular, classical biological control in Hawaii has been subject to increasing scrutiny and debate because of the highly sensitive island fauna and flora (FUNASAKI et al., 1988; HowARTH, 1991). Several authors have raised concerns about the impact of introduced fruit fly parasitoids on non-target tephritids in Hawaii (DuAn et al., 1996; DuAn and Messing, 1997, 1998; DuAn et al., 1998).

More than 30 hymenopteran parasitoids have been introduced into Hawaii for the control of pest tephritids during the last century (Wharton, 1989). Successful establishment of opiine braconids such as Fopius arisanus (Sonan), Fopius vandenboschi (Fullaway), Diachasmimorpha longicaudata (Ashmead), Diachasmimorpha tryoni (Cameron), Psyttalia incisi (Silvestri), and Psyttalia fletcheri (Silvestri), has resulted in significant suppression of pest tephritids (WHARTON, 1989). F. arisanus is the only extant species attacking host eggs. Fopius vandenboschi oviposits preferentially in early larval instars of hosts (RAMADAN, 2004), while the others prefer to attack older larval hosts (WHARTON, 1989). At present, F. arisanus is the dominant parasitoid in Hawaii because of its intrinsic competitive superiority against all extant larval fruit fly parasitoids (WANG et al., 2003).

The relative success of $F$. arisanus in the Hawaiian islands has stimulated exploration for other eggattacking parasitoids. Egg-attacking fruit fly parasitoids pose several advantages over larval parasitoids as biological control agents. For example, they attack hosts at the earliest stage when they are accessible near the fruit surface. Once fly larvae disperse into fruit tissues, especially in large fruits, larval parasitoids may be unable to locate the hosts. Therefore, introduction of effective egg-larval parasitoids is the preferred approach in Hawaii and elsewhere in the world.

Two additional egg-attacking tephritid fruit fly parasitoids from east Africa, Fopius ceratitivorus Wharton and Fopius caudatus (Szépligeti) have recently been introduced into quarantine in Guatemala (Lopez et al., 2003) and via Guatemala into Hawaii 
(BOKONON-GANTA et al., 2004). F. ceratitivorus is a newly discovered species (Wharton, 1999). Quarantine tests showed that $F$. ceratitivorus has the potential to contribute to biological control of the Mediterranean fruit fly, Ceratitis capitata (Wiedemann) (LoPEz et al., 2003; BoKonon-Ganta et al., 2004). F. caudatus (= Opius caudatus or Biosteres caudatus) was recorded as a parasitoid of $C$. capitata (WhARTON, 1999), but little is known about the biology of this species. Information on the potential impacts of the three Fopius species on non-target tephritids is also lacking.

There are 33 non-target tephritid flies in Hawaii, including 26 endemic species, and five deliberately introduced and two inadvertently introduced weed control agents (Hardy and Delfinado, 1980). Among the 26 endemic species, 21 species belong to the genus Trupanea, 19 of which are flowerhead feeders (HARDY and Delfinado, 1980). All the endemic Hawaiian Trupanea have similar life history traits and infestation ecology (Hardy and Delfinado, 1980). Trupanea dubautiae (Bryan) is an abundant species infesting flowerheads of the native Asteraceae shrub Dubautia raillardioides Hillebrand that grows in mesic forests of Kauai island (DuAn et al., 1996). It is important to protect these native flowerhead feeders from attack by introduced biological control agents because they are important pollinators for rare and endemic plants in Hawaii.

Recently, a series of retrospective studies has investigated the potential non-target impacts of introduced larval fruit fly parasitoids in Hawaii (DuAn et al., 1996; Duan and Messing, 1997, 1998; DuAn et al., 1998). To date, field surveys have not discovered any introduced fruit fly parasitoids emerging from endemic flowerhead-feeding tephritids (DuAN et al., 1996). Likewise, laboratory tests did not show that any flowerhead-feeding tephritids were likely to be attacked by larval fruit fly parasitoids, because of the lack of a positive behavioural response to flower microhabitats (DuAn and Messing, 1997, 1998). However, the larval parasitoids, D. tryoni and D. longicaudata were found to attack two nontarget gall-forming tephritids, Eutreta xanthochaeta (Aldrich) and Procecidochares utilis (Stone), which are themselves introduced weed biological control agents (DuAn et al., 1996, 1998).

Although a strong body of evidence from previous studies has indicated the safety of opiine braconids in Hawaiian ecosystems, evaluation of non-target impact of any newly introduced opiine parasitoid is still prudent. In this study, we evaluate the potential impact of three Fopius parasitoids on the endemic tephritid T. dubautiae. Because insect parasitism is the result of a sequence of directed searching behaviours at progressively finer environmental levels, from host habitat location to host location to host acceptance (WANG and Keller, 2002), we focused on the evaluation of host microhabitat-locating behaviour, i.e. the ecological suitability of non-target tephritid microhabitats to the parasitoids. Such an approach may help us to predict the non-target risk of similar endemic flowerhead-feeding tephritids and to narrow down effective host test range.

\section{Materials and Methods}

\subsection{Test parasitoids and their normal hosts}

We used $C$. capitata as the normal host of the three test parasitoids: F. arisanus, F. caudatus, and F. ceratitivorus. All tests were conducted under laboratory conditions with F. arisanus at the Kauai Agricultural Research Center (KARC, $23 \pm 2{ }^{\circ} \mathrm{C}, 60-80 \mathrm{RH} \%, 12 \mathrm{~L}: 12 \mathrm{D}$ ), Kauai, and the other two parasitoids at the quarantine facility of the Hawaiian Department of Agriculture (HDOA, $25 \pm 2{ }^{\circ} \mathrm{C}$, 70-90 RH\%, 12 L : 12 D), Honolulu, Hawaii.

Fopius arisanus was provided by the USDA-ARS Pacific Basin Agricultural Research Center (PBARC), Honolulu, Hawaii. Parasitized puparia were shipped to KARC weekly. Colonies of both $F$. caudatus and $F$. ceratitivorus were reared in the quarantine facility of HDOA on $C$. capitata using papaya as host fruit (BoKONON-GANTA et al., 2004). In all tests we used female wasps of each species that had been housed with an approximately equal proportion of males in holding cages $(25 \times 25 \times 25 \mathrm{~cm})$ for $1-2$ weeks after emergence, with water and food provided but deprived of hosts prior to tests. Thus the female wasps used in this study were naïve (without oviposition experience) and sexually mature with an expected high mature egg-load (RAMADAN et al., 1992; WANG and Messing, 2003a).

Colonies of C. capitata were maintained at the KARC and the Fruit Fly Biological Control Laboratory of the University of Hawaii at Manoa, Honolulu from eggs or puparia provided by PBARC. Adult flies (10-12-day-old) were used to obtain C. capitata egg-infested papaya fruits for later tests with the three Fopius species (for detailed procedures see $\mathrm{W}_{\mathrm{ANG}}$ and Messing, 2003b). In all tests we used papaya, Carica payaya as a host fruit of $C$. capitata. All fruits were purchased from local stores, and were washed and kept in the refrigerator at $7^{\circ} \mathrm{C}$ for 3-5 days before being used for experiments, to kill any naturally infested fly eggs (HARRIS and Bautista, 1996). One day prior to the tests, individual papaya fruits were exposed to approximately 100 pairs of adult $C$. capitata flies in a cage $(25 \times 25 \times 25 \mathrm{~cm})$ for $24 \mathrm{~h}$ for egg infestation. To facilitate egg-laying by $C$. capitata and standardize the sample for the estimation of host egg density per fruit for later tests, 50 needle punctures were evenly made on each fruit surface before exposure, so that the flies laid

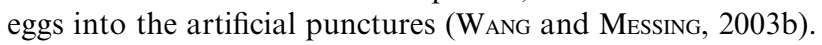
Each $C$. capitata egg-infested papaya fruit served as a test unit of host and host substrate (microhabitat).

\subsection{Collection of Trupanea dubautiae and its host plant}

All T. dubautiae used in this study were collected around Pihea trail at Kokee State Park, Kauai, at approximately 1270 m elevation, where several previous studies used T. dubautiae for field surveys and non-target tests with larval fruit fly parasitoids (Duan et al., 1996; Duan and Messing, 1997, 1998). D. raillardioides blooms from February to May. Each individual inflorescence consists of 200-700 flowerheads. According to Duan et al. (1996), the phenology of T. dubautiae is closely related to four phenological stages of flowerheads of D. raillardioides: pre-blooming stage, at which peduncles of each inflorescence are not fully expanded and petals are not visible; full-blooming stage, at which peduncles of the inflorescence are fully expanded; petal fall stage, at which all petals start falling; and mature stage, at which flowerheads have lost all petals and started to mature seeds. At pre-blooming stage, $D$. raillardioides flowerheads contain mostly $T$. dubautiae eggs and first to second instars, while in the later two stages most flowerheads contain mature larvae or puparia. 
Information on the basic reproductive biology of T. dubautiae has not been previously reported, so we first conducted preliminary observations on the fly's oviposition behaviour. In February 2004, flowerheads of D. raillardioides containing mature larvae and puparia of $T$. dubautiae were collected from the field, and individual inflorescences were plugged into $50-\mathrm{ml}$ vials with the stem (approximately $5 \mathrm{~cm}$ ) immersed in water, and brought back to the laboratory at KARC. After approximately 2 weeks, adult flies started to emerge. It was observed that newly emerged adult $T$. dubautiae were not reproductively mature. Mating occurred 4-5 weeks post-eclosion, and females started ovipositing 5-6 weeks post-eclosion. Females laid eggs directly inside flowerheads. They walked upon and examined flowerheads while probing and inserting the ovipositor into the flowerheads. Oviposition followed probing and lasted approximately $3-5 \mathrm{~min}$.

Dissection of field-collected flowerheads in the first week of March 2004 showed that each flowerhead contained a mean of $0.8 \pm 0.1 \quad(n=50) \quad T$. dubautiae eggs and $0.3 \pm 0.1$ $(n=50)$ first instars. Thus, for the later tests we collected flowerheads of $D$. raillardioides at pre-blooming stage during March 2004. Each inflorescence (consisting of 100-200 flowerheads, approximately $8 \mathrm{~cm}$ high and $10 \mathrm{~cm}$ diameter) was plugged into a $50-\mathrm{ml}$ vial filled with water, and served as a test unit of the non-target host microhabitat.

\subsection{Experimental set-up}

The test protocol was similar for each parasitoid species. Each test consisted of two treatments: a choice test and a no-choice test. All tests were conducted in screen cages $(25 \times 25 \times 25 \mathrm{~cm})$ with honey and water provided.

In the choice test, we placed a fruit test unit and a flowerhead test unit inside a cage. The fruit was placed on a vial on a stand at about the same height as the flowerheads in the middle of the cage approximately $10 \mathrm{~cm}$ apart. Twenty female wasps of either species were transferred from their holding cages into a $35-\mathrm{ml}$ plastic vial using an aspirator, which was placed upright in the middle between the fruit and the flowerhead test units. In the no-choice test, 20 females were released into a cage but only the flowerhead test unit was provided in the cage. Tests for each parasitoid species were replicated five times, each using a new cohort of parasitoids.

Each test started at $09: 30 \mathrm{~h}$ and finished after $24 \mathrm{~h}$ exposure the following day. During the first day, two observation sessions (one in the morning and the other in the afternoon) were made, each consisting of $2 \mathrm{~h}$. At $15 \mathrm{~min}$ intervals we checked each test unit once and recorded the total number of the wasps on the fruit and flowerheads. The detailed host-location behaviour of $F$. arisanus has been described (WAng and Messing, 2003c). Preliminary observation showed that the host-location behaviour of the other two Fopius was similar to F. arisanus (X. G. WANG et al., unpubl. data). Thus, during each sampling, the number of wasps that were displaying either probing (the wasp raises her abdomen, bends her ovipositor, and drills the ovipositor inside the substrate, or pushes her ovipositor back and forth while drilling) or stinging the host (the wasp keeps her body motionless while she inserts her ovipositor into the substrate) was also recorded. The morning session started $30 \mathrm{~min}$ after the release (i.e. from 10:00 to 12:00 h) when most of the wasps had left the vial; the afternoon session was conducted from 14:00 to 16:00 h. During each observation session, papaya fruit and flowerhead positions were exchanged after the first $1 \mathrm{~h}$ observation. In total, there were nine samplings for each observation session.

After the $24 \mathrm{~h}$ exposure, the papaya fruit and flowerheads were collected from the cage. Ten sub-samples of egg clusters were arbitrarily removed from each side of the papaya fruit by carefully cutting out fruit tissue around a puncture, and all eggs in each puncture were dissected under a stereomicroscope to determine the number of parasitoid eggs laid inside each host egg. Whenever the egg density was higher than 20 in a given puncture, we randomly dissected 20 eggs to estimate the total number of parasitoid ovipositions in the puncture. The actual number of ovipositions by each of the parasitoids during the $24 \mathrm{~h}$ exposure may be slightly underestimated, because some flies might not have laid eggs into the artificial punctures.

Fifteen flowerheads were randomly selected and dissected to record the number of $T$. dubautiae eggs and first instar larvae. F. arisanus was occasionally reported to attack a few first instar host larvae (NEwELl and RATHBURN, 1951), although it mainly attacks host eggs. Likewise, F. ceratitivorus rarely attacks the first instar of $C$. capitata (BoKONON-GANTA et al., 2004). However, some T. dubautiae eggs might have hatched to first instars during the $24 \mathrm{~h}$ exposure. Thus, all $T$. dubautiae eggs and first instars in the flowerheads were dissected to determine the presence or absence of the parasitoid eggs.

\subsection{Data analysis}

The data were analysed to determine if each parasitoid species preferred the normal host microhabitat rather than the non-target microhabitat in choice tests, and if each

Table 1. Behavioural responses of three Fopius egg-larval parasitoids to Dubautia raillardioides flowerheads containing Trupanea dubautiae eggs and first instars in the absence (no-choice test) or presence (choice test) of papaya fruit infested with Ceratitis capitata eggs (normal host)

\begin{tabular}{|c|c|c|c|c|c|c|}
\hline \multirow[b]{3}{*}{ Test parasitoids } & \multicolumn{4}{|c|}{ Choice test $^{1}$} & \multicolumn{2}{|c|}{ No-choice test ${ }^{1}$} \\
\hline & \multicolumn{2}{|c|}{ Frequency of visits ${ }^{2}$ to } & \multicolumn{2}{|c|}{ Frequency of probes on } & \multirow{2}{*}{$\begin{array}{c}\text { Frequency of visits } \\
\text { to flowerheads }\end{array}$} & \multirow{2}{*}{$\begin{array}{c}\text { Frequency of probes } \\
\text { on flowerheads }\end{array}$} \\
\hline & Papaya fruit & Flowerheads & Papaya fruit & Flowerheads & & \\
\hline Fopius arisanus & $39.0 \pm 2.8 \mathrm{a}$ & $4.7 \pm 1.7 b$ & $26.2 \pm 4.2$ & 0 & $6.1 \pm 1.8$ & 0 \\
\hline Fopius caudatus & $32.2 \pm 2.4 \mathrm{a}$ & $1.8 \pm 0.3 \mathrm{~b}$ & $14.8 \pm 1.0$ & 0 & $4.4 \pm 1.5$ & 0 \\
\hline Fopius ceratitivorus & $13.3 \pm 2.6 \mathrm{a}$ & $1.9 \pm 0.2 \mathrm{~b}$ & $7.7 \pm 2.3$ & 0 & $2.6 \pm 0.3$ & 0 \\
\hline
\end{tabular}


parasitoid species could successfully parasitize the non-target hosts in either choice or no-choice tests. Because the tests with $F$. arisanus were conducted under different laboratory conditions than the other two parasitoid species, we did not intend to compare the behavioural responses among the three parasitoids, although the data are presented in the same tables. Thus, all comparisons were conducted within the same species with respect to their response to different test units.

For each treatment we first calculated the total number of wasps that were observed visiting or searching (i.e. displaying probing or stinging behaviour) on each test unit based on a total of 18 samples (nine from each session), and then calculated the mean frequency of wasp visits (i.e. on the test unit) and probing per hour (a total of $4 \mathrm{~h}$ ) per replicate. This estimate reflects the relative amount of time spent by the parasitoids on the different test units and the degree of the parasitoids' behavioural responses to both microhabitats. The frequency of wasp visits or probes on the two different test units in the choice test was compared using Student's $t$-test (JMP SAS 4.01, Gray, NC).

The length of exposure time may influence a parasitoid's behavioural response. To determine if the frequency of wasp visits to different test units increased or decreased over the observational periods in both the morning and afternoon session, we analysed the relationship between the number of wasp visits $(Y)$ and observational order over a morning or afternoon session $(X)$ using linear regression (JMP SAS 4.01, Gray, NC).

\section{Results}

In the choice tests, all three Fopius parasitoid species visited $C$. capitata egg-infested papaya fruit significantly more often than flowerheads containing $T$. dubautiae eggs and larvae ( $F$. arisanus: $t_{8}=-18.1$, $\mathrm{P}<0.01 ; F$. caudatus: $t_{8}=-12.5, \mathrm{P}<0.01 ; F$. ceratitivorus: $t_{8}=-4.4, \mathrm{P}<0.01$ ) (table 1). Even when only flowerheads containing $T$. dubautiae eggs and larvae were provided in the no-choice tests, the observed frequency of wasp visits to flowerheads was also very low for all of the three tested species (table 1).

When female wasps of all three species visited C. capitata egg-infested papaya fruit, they repeatedly displayed probing behaviour before locating potential host oviposition sites. In contrast, not a single wasp of any of the three species was observed to display normal probing behaviour on flowerheads containing T. dubautiae eggs and larvae, in either choice or no-choice tests (table 1). All wasps that landed on the flowerheads appeared to be only resting (the wasp remains motionless on the flowerhead with its antennae and ovipositor stretched out laterally). Each parasitoid species successfully parasitized $C$. capitata eggs on papaya fruit during the $24 \mathrm{~h}$ exposure (table 2). However, not one of the $T$. dubautiae eggs or first instars on the flowerheads was parasitized by any of the three parasitoids in either choice or no-choice tests (table 2).

The dynamic patterns of wasp visits to the normal host microhabitats were different among the three Fopius parasitoid species in the choice tests (fig. 1). Increased frequency of wasp visits by $F$. arisanus were observed following the release during the morning

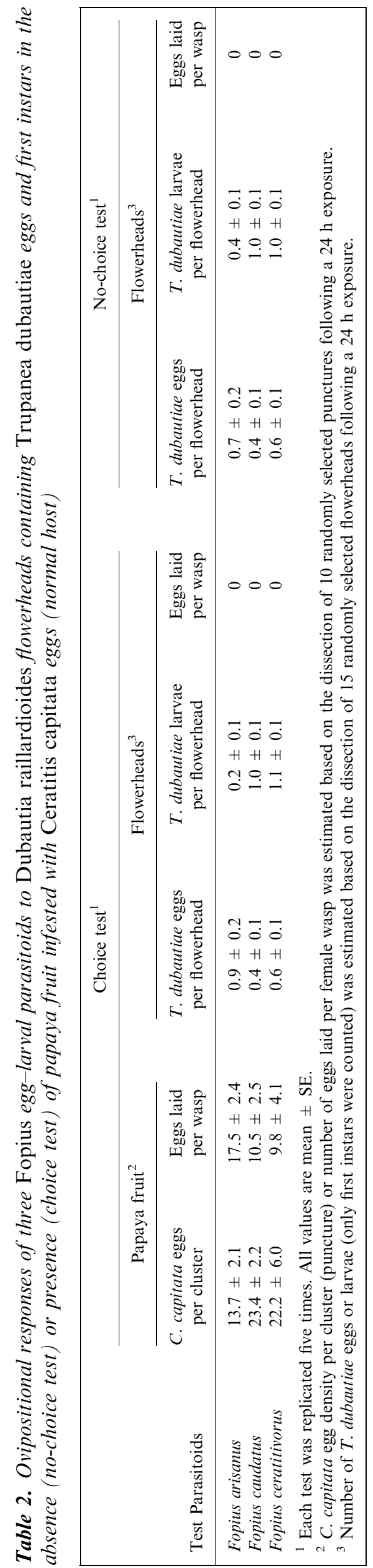



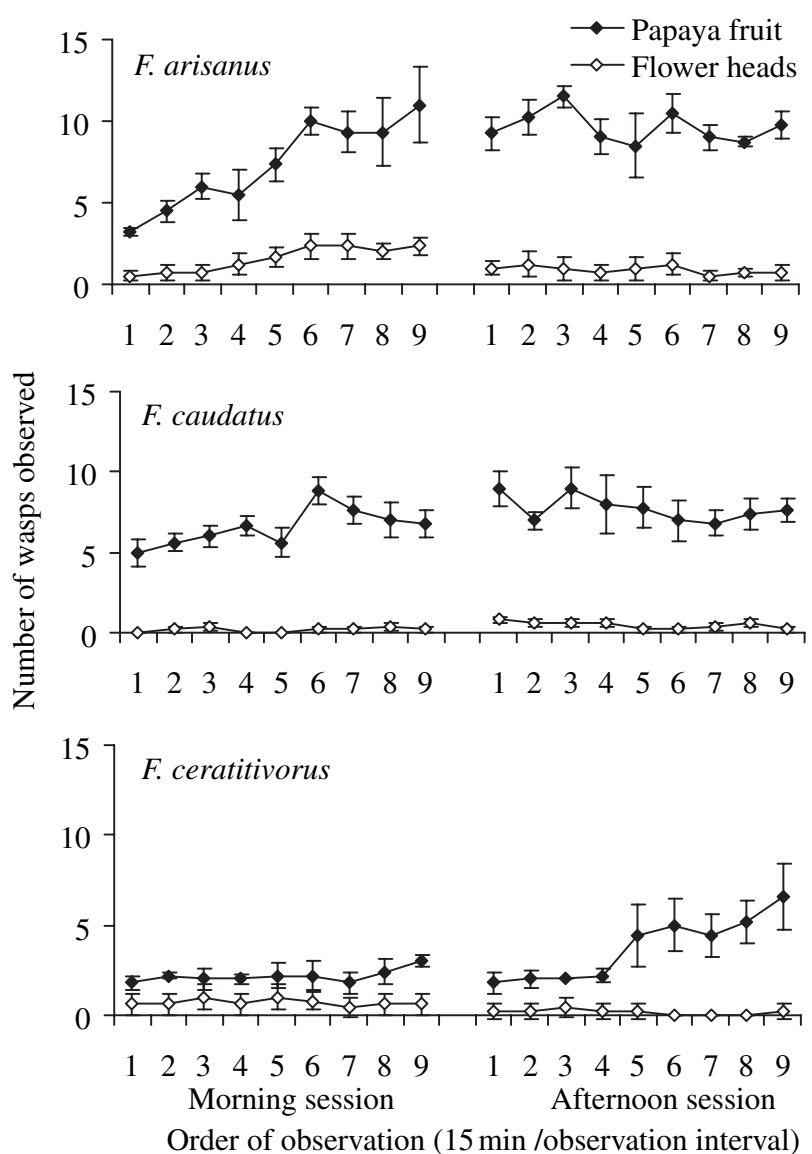

Fig. 1. Mean ( $\pm S E$ ) number of wasps of Fopius arisanus, Fopius caudatus and Fopius ceratitivorus observed on papaya fruit infested with Ceratitis capitata eggs (normal tephritid host) or Dubautia raillardioides flowerheads containing Trupanea dubautiae eggs and young larvae (non-target tephritid) in a choice test. For each test, 20 female wasps were released into a cage holding both test substrates ( $n=5$ replicates). The morning observation session started 30 min following the release and was conducted from 10:00 to 12:00 h, while the afternoon session lasted from 14:00 to 16:00 h. At 15 min intervals the numbers of wasps on both substrates was counted once

session $\left(Y=2.4+0.99 X, r^{2}=0.64, \mathrm{P}<0.001\right)$, and the number of wasp visits reached a peak at the end of the morning observation session, and kept consistently high in the afternoon $\left(Y=9.9-0.07 X, r^{2}=0.01\right.$, $\mathrm{P}=0.55)$. A similar trend was observed for $F$. caudatus (morning session: $Y=5.09+0.24 X, \quad r^{2}=0.11$, $\mathrm{P}=0.04 ; \quad$ afternoon session: $\quad Y=8.55-0.16 X$, $\left.r^{2}=0.03, \mathrm{P}=0.25\right)$. In $F$. ceratitivorus, only a few wasps were observed visiting papaya fruit in the morning and there was no significant increase over the entire morning session $(Y=1.74+0.09 X$, $\left.r^{2}=0.04, \mathrm{P}=0.19\right)$, until the afternoon when more and more wasps were observed to visit the fruit $\left(Y=0.7+0.61 X, r^{2}=0.30, \mathrm{P}<0.001\right)$.

Overall, the frequency of wasp visits to flowerheads was always low (less than two females per observation) in both choice and no choice tests (figs 1 and 2). There was no significant increase or decrease in the frequency

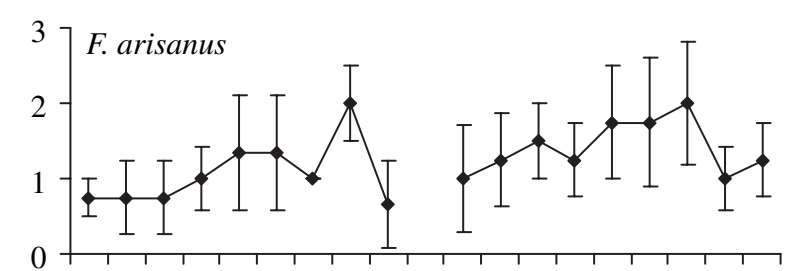

$\begin{array}{llllllllllllllllll}1 & 2 & 3 & 4 & 5 & 6 & 7 & 8 & 9 & 1 & 2 & 3 & 4 & 5 & 6 & 7 & 8 & 9\end{array}$
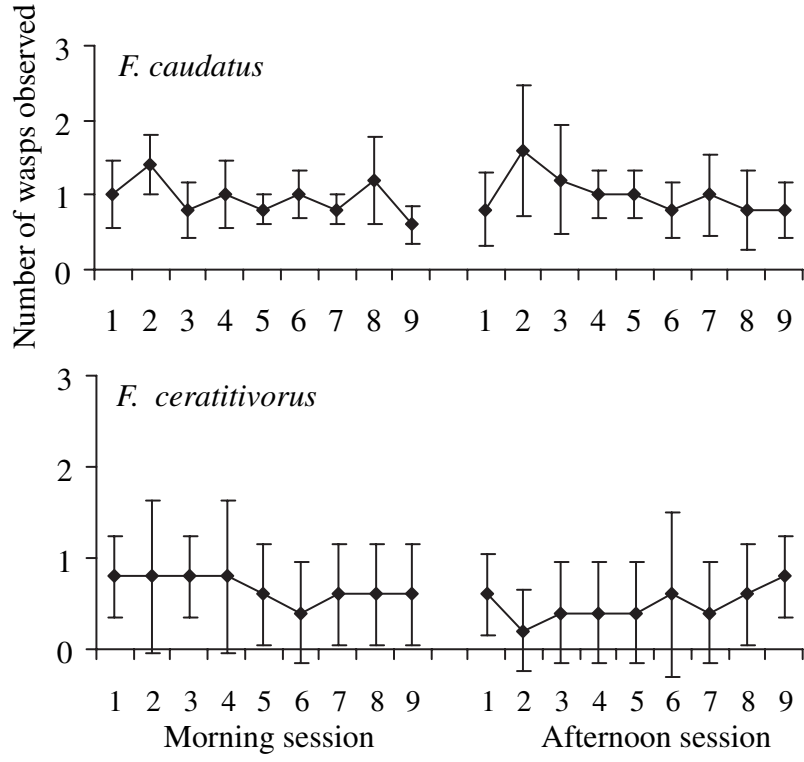

Order of observation ( $15 \mathrm{~min} /$ observation interval)

Fig. 2. Mean ( $\pm S E$ ) number of wasps of Fopius arisanus, Fopius caudatus and Fopius ceratitivorus observed on Dubautia raillardioides flowerheads containing Trupanea dubautiae eggs and young larvae (non-target tephritid) in no-choice test. For each test, 20 female wasps were released into a cage holding the test substrates ( $n=5$ replicates). All observations were consistent with the choice test (see description in fig. 1)

of visits to the flowerheads over the observational periods by any of the three species (all $\mathrm{P}>0.05$ ).

\section{Discussion}

Our results show that all three egg-attacking parasitoids, $F$. arisanus, $F$. caudatus and $F$. ceratitivorus, lack normal ovipositional responses to $T$. dubautiae in its native host plant, $D$. raillardioides flowerheads. This is consistent with several previous studies in which all tested larval fruit fly parasitoids, including $D$. longicaudata, D. tryoni, P. fletcheri, and Tetrastichus giffardianus Silvestri, also lack ovipositional responses to $T$. dubautiae larvae-infesting $D$. raillardioides flowerheads (Duan and Messing, 1997, 1998). Although all the females used in this study were naïve and sexually mature, they did not show increasing behavioural responses to non-target host microhabitats over time (figs 1 and 2). As a result, none of the three Fopius species was able to locate $T$. dubautiae.

Although $F$. arisanus and several introduced larval fruit fly parasitoids are widely established in Hawaii, none of the numerous field surveys conducted in Hawaii (Funasaki et al., 1988; Duan et al., 1996) 
discovered introduced fruit fly parasitoids emerging from $T$. dubautiae or any other endemic tephritid. To date, only $D$. longicaudata and $D$. tryoni were found to attack the gall-forming tephritids, E. xanthochaeta and $P$. utilis in the field (DuAN et al., 1996, 1998). In laboratory tests female $D$. longicaudata, D. tryoni and T. giffardianus also showed ovipositional responses to the Hamakua pamakani gall fly, Procecidochares alani L. (an introduced weed biological control agent), but field surveys did not find any introduced fruit fly parasitoids associated with this gall fly (Purcell et al., 1997). Recently, a test in quarantine also showed that $F$. ceratitivorus is unlikely to attack P. alani (BoKononGanta et al., 2004).

Visual (fruit shape, size and colour) and olfactory stimuli emitted by ripening and host-infested fruits have been shown to play an important role in host microhabitat recognition of opiine braconids attacking fruit-inhabiting tephritids (VARGas et al., 1991; MESSING and JANG, 1992; HARris and Bautista, 1996). Among the three Fopius parasitoids, the host-searching behaviour of $F$. arisanus is well documented. Physical appearance of host fruits is an important cue for host habitat location by female $F$. arisanus, with light colours (yellow and white) more attractive than other colours (VARGAs et al., 1991). Host fruit species, size, shape and ripeness all have been shown to influence parasitism by $F$. arisanus (VARGAS et al., 1991; Harris and BAutista, 1996). Other stimuli important to the parasitoid's attraction to potential host microhabitats are the presence of host-associated cues (e.g. host oviposition scars and adult fly residues of $C$. capitata) (WANG and Messing, 2003c). Thus, host microhabitat selection plays a central role in the process of host selection in opiine fruit fly parasitoids. Duan and Messing (1997) suggest that the fruit-like spheroid shape of a gall may be similar enough to a small fruit to elicit hostsearching behaviour in some larval fruit parasitoids. However, flowerheads of Asteraceae shrubs have no resemblance at all to the host fruits of frugivorous tephritids.

Several authors have emphasized the importance of ecological host range for non-target testing of parasitoids (e.g. Duan and Messing, 1997; Messing, 2001). However, most non-target host range tests focus on host acceptance and suitability, i.e. the last steps in the hierarchy leading to parasitism, rather than commencing with locating host habitats. For example, many non-target host tests for weed biological control focus on the evaluation of introduced agents on taxonomically or phylogenetically related species to the target host plants [using centrifugal phylogeny as a basis for non-target test (Messing, 2001)]. This method may prove effective for non-target test of weed biocontrol agents, but may be unrealistic in parasitoids (MEssing, 1999, 2001). It has been shown that when non-target tephritids were removed from their natural microhabitats and placed on an artificial substrate of target fruit flies, some larval fruit fly parasitoids can attack the non-target hosts (e.g. Duan and Messing, 1998). Obviously, this is artificial, and ecologically unrealistic. The physiologically suitable non-target tephritid flies are not ecologically suitable, simply because the wasps are unable to recognize the microhabitat (DuAN and Messing, 1997, 1998). Host specificity of insect parasitoids arises from behavioural and physiological adaptations that limit the range of organisms that they will attack and utilize as hosts. Behavioural adaptation precedes physiological adaptation in the evolution of host specificity (Futuyma and Moreno, 1988), thus understanding the behavioural basis of host specificity or behavioural evaluation in host range tests is critical. This study confirms the importance of understanding host habitat location behaviour for non-target tests in fruit fly parasitoids that narrow down effective host test range.

Because of the lack of ovipositional response by the three Fopius species to the $T$. dubautiae-infesting flowerhead feeders of Asteraceae plants, we conclude that endemic flowerhead feeders are at minimal risk from introduced egg-attacking fruit fly parasitoids.

\section{Acknowledgements}

We thank the USDA-ARS Pacific Agricultural Research Center for providing $F$. arisanus and C. capitata eggs and puparia, and the Department of Land and Natural Resources of the State of Hawaii for granting us a permit to sample $T$. dubautiae and its host plant $D$. raillardioides in the Kokee Natural Reserve areas on the Island of Kauai. We also thank K. Teramoto (Hawaii Department of Agriculture) for the use of the quarantine facility, and one anonymous reviewer for useful comments on an early version of this manuscript. This research was supported by USDA-ARS grant no. 5853208147 to R.H.M, X.G.W and A.H.B. This is Publication No. 4693 of the College of Tropical Agriculture and Human Resources Journal Series.

\section{References}

Bokonon-Ganta, A. H.; Ramadan, M. M.; Wang, X. G.; Messing, R. H., 2004: Biological performance and potentials of Fopius ceratitivorus (Hymenoptera: Braconidae), an egg-larval parasitoid of tephritid fruit flies, newly imported to Hawaii. Biol. Control (still in press).

Duan, J. J.; Messing, R. H., 1997: Effect of two opiine parasitoids (Hymenoptera: Braconidae) introduced for fruit fly control on a native Hawaiian tephritid, Trupanea dubautiae (Diptera: Tephritidae). Biol. Control 8, 177184.

Duan, J. J.; Messing, R. H., 1998: Effect of Tetrastichus giffardianus (Hymenoptera: Eulophidae) on non-target flowerhead-feeding tephritids (Diptera: Tephritidae). Environ. Entomol. 27, 1022-1028.

Duan, J. J.; Purcell, M. E.; Messing, R. H., 1996: Parasitoids of non-target tephritid flies in Hawaii: implications for biological control of fruit fly pests. Entomophaga 41, 245-256.

Duan, J. J.; Messing, R. H.; Purcell, M. F., 1998: Association of the opiine parasitoid Diachasmimorpha tryoni (Hymenoptera: Braconidae) with the lantana gall fly (Diptera: Tephritidae). Environ. Entomol. 27, 419-426.

Funasaki, G.; Lai, P. Y.; Nakahara, L. M.; Beardsley, J. W.; Ота, А. K., 1988: A review of biological control introductions in Hawaii: 1890-1985. Proc. Hawaiian Entomol. Soc. 28, 105-160.

Futuyma, D. J.; Moreno, G., 1988: The evolution of ecological specialization. Annu. Rev. Ecol. Syst. 19, 207-234. 
Hardy, D. E.; Delfinado, M. D., 1980: Insect of Hawaii. Vol. 13. Diptera: Cyclorrhapha III. Honolulu, HI: University of Hawaii Press, 122-135.

Harris, E. J.; Bautista, R. C., 1996: Effects of fruit fly host, fruit species, and host egg to female parasitoid ratio on the laboratory rearing of Biosteres arisanus. Entomol. Exp. Appl. 79, 187-194.

Howarth, R. G., 1991: Environmental impacts of classical biological control. Annu. Rev. Entomol. 36, 485-509.

Lopez, M.; Sivinski, J.; Rendon, P.; Holler, T.; Bloem, K.; Copeland, R.; Trostle, M.; Aluja, M., 2003: Colonization of Fopius ceratitivorus, a newly discovered African eggpupal parasitoid (Hymenoptera: Braconidae) of Ceratitis capitata (Diptera: Tephritidae). Florida Entomol. 86, 5360.

Messing, R. H., 1999: The impact of nontarget control on the practice of biological control. In: Non-target Impact of Biological Control. Ed. by Follett, P. A.; Duan, J. J. Norwell, MA: Kluwer Academic Publishers, 45-55.

Messing, R. H., 2001: Centrifugal phylogeny as a basis for non-target host testing in biological control: is it relevant for parasitoids? Phytoparasitica 29, 187-190.

Messing, R. H.; JANG, E. B., 1992: Response of the fruit fly parasitoid Diachasmimorpha longicaudata (Hymenoptera: Braconidae) to host fruit stimuli. Environ. Entomol. 21, 1189-1195.

Newell, L. M.; Rathburn, F., 1951: Evaluation of Effectiveness of Natural Enemies of Fruit Flies. University of Hawaii, Agricultural Experimental Station, Entomology Department, Quarterly Report, April-June 1951. Honolulu, HI: University of Hawaii.

Purcell, M. E.; Duan, J. J.; Messing, R. H., 1997: Response of three hymenopteran parasitoids introduced for fruit fly control to a gall-forming tephritid, Procecidochares alani (Diptera: Tephritidae). Biol. Control 9, 193-200.

Ramadan, M. M., 2004: Mass-rearing biology of Fopius vandenboschi (Hym., Braconidae). J. Appl. Entomol. 128, 226-232.

Ramadan, M. M.; Wong, T. T. Y.; Beardsley, J. W., 1992: Reproductive behavior of Biosteres arisanus (Sonan)
(Hymenoptera: Braconidae), an egg-larval parasitoid of the oriental fruit fly. Biol. Control 2, 28-34.

Vargas, R. I.; Stark, J. D.; Prokopy, R. J.; Green, T. A., 1991: Response of oriental fruit fly (Diptera: Tephritidae) and associated parasitoids (Hymenoptera: Braconidae) to different color spheres. J. Econ. Entomol. 84, 1503-1507.

WANG, X. G.; Keller, M. A., 2002: A comparison of hostsearching efficiency of the two larval parasitoids of Plutella xylostella. Ecol. Entomol. 27, 105-114.

WAng, X. G.; Messing, R. H., 2003a: Egg maturation in the parasitoid Fopius arisanus (Hymenoptera: Braconidae): do host-associated stimuli promote ovarian development? Ann. Entomol. Soc. Am. 96, 571-578.

WAnG, X. G.; Messing, R. H., 2003b: Intra- and interspecific competition by Fopius arisanus and Diachasmimorpha tryoni (Hymenoptera: Braconidae), parasitoids of Mediterranean fruit fly Ceratitis capitata (Diptera: Tephritidae). Biol. Control 27, 251-259.

WAnG, X. G.; Messing, R. H., 2003c: Foraging behavior and patch time allocation by Fopius arisanus, an egg-larval parasitoid of tephritid fruit flies. J. Insect Behav. 16, 593612.

Wang, X. G.; Messing, R. H.; Bautista, R. C., 2003: Competitive superiority of early acting species: a case study of opiine fruit fly parasitoids. Biocontrol Sci. Tech. 16, 391-402.

Wharton, R. A., 1989: Classical biological control of fruit Tephritidae. In: World Crop Pests. Fruit Flies: Their Biology, Natural Enemies, and Control, Vol. 3b. Ed. by Robinson, A.; Harper, G. Amsterdam: Elsevier Science, 303-313.

Wharton, R. A., 1999: A review of old world genus Fopius, with description of two new species reared from fruitinfesting tephritidae. J. Hymen Res. 8, 48-64.

Author's address: X. G. WANG (corresponding author), Department of Plant and Environmental Protection Sciences, University of Hawaii, 7370 Kuamoo Road, Kapaa, HI 96746, USA. E-mail: xingeng@hawaii.edu 